\title{
The Challenges of South African Teachers in Teaching Euclidean Geometry
}

\author{
Simon A. Tachie \\ University of the Free State, South Africa \\ https://orcid.org/0000-0003-1535-7312
}

\begin{abstract}
The current study identifies challenges confronting teachers in the teaching of Euclidean geometry in schools. This qualitative case study purposefully selected ten schools situated in the Motheo District of Education, Free State, South Africa. Data was generated using classroom observations and focus group interviews. The findings revealed that the majority of the teachers lacked mathematical subject content knowledge as well as pedagogical content knowledge to teach geometry effectively. In many cases, redeployment of teachers led to teachers being illequipped to teach specific subjects, such as mathematics. Recommendations have been made to enhance effective teaching and learning of mathematics (geometry in this case) in schools.
\end{abstract}

Keywords: Euclidean geometry; Subject content knowledge; Pedagogical content knowledge; Teacher challenges; Mathematics teaching

\section{Introduction}

Since the birth of democracy in South Africa in 1994, education has experienced curriculum reforms with changes affecting all levels of education, mathematics included. These changes have retained the review and reform of the mathematics curriculum, and this has impacted on teachers' content knowledge as many teachers, during both their secondary and teacher education, did not study some of the newly introduced mathematical concepts such as Euclidean geometry. Morris (1985, p.92) argues that "the root cause of poor geometry teaching lies in the mismatch between teacher education courses and the needs of the learners in the school," meaning that teachers have been trained on some aspects of geometry which are not related to what they are to teach in a classroom situation. These teachers, in most cases, find themselves inadequately prepared to teach Euclidean geometry as expected of them since they are not conversant with the use of relevant skills and strategies (Luthuli, 1996).

Related studies have increasingly emphasized geometry education research, which recommends the use of technological tools such as dynamic geometry software in the teaching and learning of geometry. These studies have indicated how the use of technologic tools impacts on learners' geometrical thinking skills 
(especially on the teaching and learning of geometrical reasoning and proving), on teachers' geometric content knowledge, and teacher development for geometry education (Jones \& Tzekaki, 2016). However, little is known about how South African mathematics teachers use those technological tools since geometry had not initially been included in the curriculum. To throw more light on the above issue, teachers graduating from the universities from 2013 had not studied Euclidean geometry during their formal education, either in their secondary school education or in tertiary training. The challenges of handling Euclidean geometry by these teachers are, therefore, more problematic than for those teachers who have studied the subject and who have not trained adequately for teaching classroom Euclidean geometry. This under-teaching or non-teaching of Euclidean geometry poses a severe threat to the performance of the learning of mathematics, hence the current study. This study aimed to identify all challenges experienced by these teachers in the teaching of geometry in schools and to find solutions to the problem at hand. In this case, it was to support mathematics classroom teachers in the teaching/learning of mathematics in the schools of the Motheo education district of Free State, South Africa. In light of the preceding, this primary research question is: What are the main challenges faced by teachers in teaching/learning of geometry in schools?

\section{Teaching of Geometry}

Studies have shown that geometry is not only difficult for learners who have to learn the subject, but similarly for the teachers who have to teach it. Teachers lack subject content knowledge and also the understanding of other strategies to teach the subject to perfection since it deals with practical activities. Focus on geometrical skills is also vital in areas of construction work, architectural design, and engineering (Ubah \& Bansilal, 2019; Alex \& Mammen, 2018). Much of the geometry teaching in the country has been based on immersive and adaptive instruction and learning where teachers move from a conceptual approach (the sensible application of procedures) to a procedural approach (calculation accuracy). Scholars such as Brown (1999) and Khoo and Clements (2001) affirmed that learners have an inadequate understanding of geometrical concepts, reasoning, and problem-solving skills. The afore-mentioned statement supports the analysis of the National Senior Certificate (NSC) diagnostic report per question, which shows a declining performance of learners in Mathematics paper 2, particularly in Euclidean geometry (Chihanbakwe, 2017).

Brannan et al. (2002) stated that geometry is a branch of mathematics concerned with the properties of configurations of points, lines, angles, circles, and the most basic of these figures. It deals with axioms and proofs of theorems through deductive thinking (Mamali, 2015). Bassarear (2012) defined geometry as "the study of shapes, their relationships, and properties." In the same way, Güven and Kosa (2008) maintain that geometry is the study of space and shape in which more excellent reasoning capability is necessary to understand the concept well. From these definitions of geometry, it is quite clear that when dealing with geometry, the focus is on identifying shapes, measuring different aspects of those shapes, and categorizing such shapes according to their properties. 
Geometry originated from several ancient cultures, including Indian, Babylonian, Egyptian, and Chinese cultures (Ding \& Jones, 2006; Jones, 2002). These ancient cultures used geometry to measure lengths, heights, angles, directions, and distances. Geometry is an axiomatic and deductive study of mathematics is linked to critical thinking and logical reasoning. There are different types of geometries depending on the planes, angles, and approaches they take. Coordinate (analytical geometry), as an example, is Cartesian-plane driven.

The British Mathematician, Sir Christopher Zeeman saw geometry as that which comprises those branches of mathematics that exploit visual intuition, the most dominant of our senses, requiring remembering of theorems, understanding of proofs, inspiring of conjectures, perceiving of reality, and giving global insight (Jones, 2002). Indeed, those who are geometrically inclined tend to have a high level of memory restoration and can easily link or relate events and occurrences, and this is one of the reasons why Euclidean geometry was introduced as a core topic in the South African school curriculum.

\subsection{The teaching of Geometry in South African schools}

According to Kotzé (2007), Euclidean geometry (or - bodies of knowledge consisting of statements justified by proofs, which depend on mathematical axioms and an underlying logic) requires educators to assist learners in linking new knowledge to existing knowledge and develop instructional techniques that would facilitate cognitive growth and change during teaching and learning. Studies have shown that geometry occupies a significant role in the teaching of mathematics in global perspectives. For example, it provides a rich source of visualization for understanding arithmetic, algebraic, and statistical concepts, as indicated by Binti et al. (2003). Furthermore, in the scientific world, the importance of geometry appears naturally in many sectors of the planet, such as the structure of the solar system, in geological information, rocks and crystals, flowers, and even in animals for specific purposes. The importance of geometry in the lives of people cannot be overemphasized. However, many teachers find it challenging to teach the concept in South Africa due to the lack of subject content knowledge and lack of cognitive skills. Adolphus (2011) stated that one of the problematic ideas that teachers struggled to teach in mathematics is Euclidian geometry, because of the technicalities related to the language, visualization of objects for better identification of properties, and inadequate conceptual understanding. Freudenthal (1991) asserted that teaching and learning of mathematics must be connected to reality, meaning that in the teaching of geometry, teachers should try to make use of available materials at their disposal to convey the meaning of geometrical concepts which pose a threat to the learning of geometry in schools. Researchers such as Freudenthal (1991), Sanni (2007), Van Den Heuvel-Panhuizen (2003), and Wigley (1994) have disputed the notion that a teaching approach which connects to reality helps learners develop and apply mathematics to problem and help makes sense.

It was evident from the assertion of Sanni (2007) that instruction of geometry concepts was bedevilled regimented mathematics classroom practices such as checking homework, followed by teacher lecture and demonstration, followed in 
turn by learner practice in a sequence of classroom instructional activities (Sanni, 2007). Such an approach does not take into account Van Hiele's (1986) five levels of geometry thinking, which serve as a rational basis for the teaching of geometry in schools. These levels are:

Level 1: Recognition /Visual Level: Learners recognize figures by their appearance.

Level 2: Descriptive/Analytic: Learners recognize/analyse figures by their properties.

Level 3: Abstract/Relational/Ordering: Learners distinguish between necessary and sufficient conditions for a concept. They can also form abstract definitions and classify figures by elaborating on their interrelationships.

Level 4: Formal Deduction: Learners establish theorems within an axiomatic system. They recognize the difference between undefined terms, definitions, axioms, and theorems. They can construct original proofs.

Level 5: Mathematical Rigor: Learners understand the relationship between various systems of geometry. They can describe the effect of adding or deleting an axiom on a given geometric system and can compare, analyse, and create proofs under different conditions.

Van Hiele (1986) believes that these five sequential geometric levels are needed for identification and sorting, developing critical thinking and problem-solving skills, formulating conjectures, intuition, postulation, deductive reasoning, logical arguments, and proof formulation. The question that comes to mind is whether teachers are applying the above level as indicated by Van Hiele (1986), and also to establish what teachers are currently doing in the teaching and learning of geometry in schools. Mcyntire's (2018) views are confirmed when he states that Van Hiele's theory of geometrical thinking is the theory behind the teaching of Euclidean geometry in schools. Many educators still prefer using the traditional teaching approach in the education of geometry in schools.

South Africa has seen various curriculum reforms as one Minister of Education replaced another, and that has affected the teaching of Euclidean geometry in schools. The curriculum reform phenomenon has also affected other countries. China is one of the countries that underwent curriculum reforms and has seen a great deal of change in its mathematics curriculum. According to Xei (2005), China has had to adapt to curriculum reforms for the benefit of the development of society, and this was done by changing mathematics content taught to elementary (primary) and middle (junior) learners in the People's Republic of China. Xei (2005) explained that the reforms brought both successful experiences and frustrating lessons in that, through adopting a foreign mathematics curriculum from the Soviet Union (the 1950s), their cultural identity and national conditions were compromised. On the other hand, they needed to examine the superiority and limitation of Chinese mathematics education by looking at the tendencies in international mathematics education so that China's curriculum could be recognized internationally. The current study aimed to establish the applicability of the China and Soviet Union experience to that of the South African experience. 
The Chinese Ministry of Education listed six focus areas in mathematics teaching. One such focus area meant that Euclidean geometry was compulsory for all learners. The reason for this was that it had been observed that in the traditional Chinese culture, logical thinking ability had been rare, doing mathematics-related training, especially about Euclidean geometry, a great need. This indicated the importance of deductive reasoning, which is extractable from the teaching of Euclidean geometry for a nation doing it as a core topic in mathematics. However, many teachers faced challenges in teaching Euclidean geometry as it was newly introduced into the school curriculum.

In Zimbabwe, Euclidean geometry has suffered the same fate, as was the case in China. Wessels (2004, p.70) confirmed the fact that "geometry is one of the poor relatives in the field of mathematics and it is only in the past five years that its status has improved in Zimbabwe. This common occurrence has been observed in Zimbabwe's General Certificate of Education (GCE)". Students with this qualification, however, had a deficient level of understanding of Euclidean geometry as it was not comprehensively taught, which led to challenges being experienced in teaching Euclidean geometry in Zimbabwean secondary schools. A similar issue has been observed in South African schools where Euclidean geometry has seen less emphasis, if any, at some tertiary institutions resulting in education graduates having not been educated in the topic of Euclidean geometry.

Several Mathematics teaching studies focus on teachers' content knowledge, curriculum implementation, instructional strategies, teachers' competency in teaching the new mathematics curriculum, and teacher education programs (Maree \& Van der Walt, 2007; Masinga et al., 2007; Strawderman, 2010; Webb, 2010). Some teachers have already qualified as teachers yet did not undergo training on some of the newly-introduced topics such as Euclidean geometry.

In 2012, the South African curriculum for Grades R-12 saw the introduction of a new curriculum, which was an amendment of the existing National Curriculum Statement (NCS) and which did not offer Euclidean geometry as the core topic for Curriculum and Assessment Policy Statement (CAPS) for Grades R-12. According to CAPS (DBE, 2011, p.11), "Mathematics is a language that makes use of symbols and notations for describing numerical, geometric, and graphical relationships. It is defined as a human activity that involves observing, representing and investigating patterns and qualitative relationships in physical and social phenomena and between mathematical objects themselves."

Teachers who had not studied this topic in their secondary schooling or their teacher education programs found themselves teaching the subject, but with little knowledge and understanding. Their preparations were affected because preparing useful lessons for teaching mathematics depends on how one understands the mathematics content itself. Brodie et al. (2009) found that there is always a significant decline in the cognitive levels of mathematics content whenever a teacher is not comfortable with the topic, and so knowledge transfer is compromised. The same situation occurred with the teaching of Euclidean geometry. 
Turik (2000) contended that inadequate teacher knowledge in teaching such a topic becomes a challenge. The lack of subject content knowledge of Euclidean geometry and resources leads to compromising understanding of geometric concepts, and thus poor lesson preparation and teaching. This lack of subject content knowledge of Euclidean geometry affects the teachers of the Motheo Education District, hence the current study.

\section{Theoretical Framework}

The understanding of geometry and its concepts requires a great deal of basic knowledge on the part of the person learning it. Saxe (1991) quotes Piaget's work, stating that learning involves the elements of discovery and scaffolding to elevate the learner's activities to a level. In turn, this indicates that anybody who is trying to learn an aspect must use concrete objects when introducing and investigating phenomena to help the person grasp the task at hand quickly and easily pertaining to the teachers who have not studied Euclidean geometry as their level of development is unsatisfactory. The participant teachers, therefore, engaged themselves in collaborative discussions about geometry problems for a better understanding of some concepts. Thus some of their challenges in teaching the concept (geometry) were exposed.

Effectiveness in geometry teaching has been the subject of considerable theorizing. Still, teachers should draw on both subject content knowledge and pedagogical content knowledge, which is embracing theory and practice gained from ongoing teaching activities for a better understanding of a concept (Solis, 2009). Much research has been conducted on the validity of Van Hiele's (1986) theory and has focused on teachers' emphasis on geometrical reasoning. Alternatively, Pusey (2003) considered that each of Piaget's five stages of development - the sensorimotor, iconic, concrete symbolic, formal, and postformal stages - has an important role to play in the learning of geometry. The current study underpins the constructivist approach based on Piaget's cognitive theory as well as Van Hiele's theory (Piaget, 1962; Van Hiele, 1986). Even though Van Hiele's theory is intended for learners' education of mathematics, it was used in this study to identify challenges faced by teachers in the teaching of Euclidean geometry as many experience challenges in solving problems in Euclidean geometry.

These challenges were identified with pre-test activities completed before the start of this research. In defense of the teachers, many claimed that they had been forced to teach mathematics due to redeployment and were neither qualified nor equipped to teach this aspect of mathematics. This study emphasized building or constructing knowledge from small existing pieces of the knowledge base. For concrete geometric understanding, one must have spatial thinking and geometric abilities which, just like Piaget's developmental stages in learning, also involves four phases of spatial developmental thinking (Stephenson et al., 1996)

The primary mission of the Department of Basic Education is to produce competent teachers. They can offer the necessary services in the community, such 
as in the Motheo district, through quality teaching and learning (Teacher's Forum, 2009), calling for the Department to recruit teachers who can teach critical subjects like mathematics and science. However, the teaching and learning of mathematics and science in the district has been compromised since some teachers, especially mathematics teachers, are not equipped to teach specific topics such as geometry and probability, despite government reform efforts in the development of learning activities in mathematics and science. Such reforms include the introduction of geometry and other topics as compulsory topics in the CAPS curriculum.

\section{Research Methodology}

The research methodology section highlights the following aspects: general background, sample, instruments and procedures, data analysis, and ethical considerations.

\subsection{General background}

A research approach comprised approaches that are used in educational research to collect data that may be used for inferences and interpretations (Cohen et al., 2009; Ayoola, 2017). The primary purpose of the research methodology is to help understand the process of research. Creswell (2009) stated that choosing the correct method in addressing a challenge or a problem in any study plays a vital role in achieving the purpose of the study. In this study, a qualitative research approach with a case study design was used to identify and detail challenges facing teachers in the teaching of Euclidean geometry through observation and focus-group interviews to find tangible solutions to this problem in the district of Motheo.

\subsection{Sample}

Ten mathematics teachers were purposively selected from ten schools through a cluster-sampling technique. The participant teachers were grouped into three groups, with at least three participants in each group. Convenience sampling technique was used for the selection of the teachers into their respective groups to ensure that each group comprises a member from each cluster to elicit different views based on the problems they experienced in the teaching of geometry in their various clusters. The other motive was to assist the participant teachers in sharing their opinions experienced in their individual clusters to generate at least one thought that represented that particular group during focus-group interviews.

\subsection{Instrument and procedures}

Observation and focus-group interviews were used for data collection. Class observations were conducted using the participant teachers in their respective schools and video recorded. Teachers were observed on the methods they used to present their lessons and the problems they faced in delivering the content to the learners. How learners were questioned and how they discussed and debated with their peers was also noted. The way and manner in which learners responded to their teachers' questions and how they solved problems given to them by their teachers were also noted to see how the teachers' methods of teaching contributed to learners' understanding of geometry concepts. The teachers were later invited to participate in a collaborative discussion using the recorded videos to examine 
the phenomenon through discussions and interviews. During focus groupinterviews, when a question was directed to a particular group, each member of the group was given equal opportunity to respond.

In contrast, other group members attentively listened to their responses. If that group had no valid or pertinent response, the question was transferred to another group for their opinion until all questions were exhausted. The data gathered offered evidence of teachers' practice in the teaching of Euclidean geometry, bearing in mind Van Hiele's levels of geometric thought (cited in Van de Walle et al., 2013). This paved the way for participants to deliberate on the issues of concern to identify a reliable solution to the problem identified or discussed.

\subsection{Data analysis}

In this study, relational content analysis was used. After repeatedly read through to identify the main themes, the data were examined in-depth to provide detailed descriptions of the participant teachers. The data were coded, categorized, and grouped them into themes for interpretation and reporting. Nili et al. (2017) stated that focus group data can be analyzed quantitatively (e.g., through participants vote counting) after or in parallel with the primary/qualitative analysis. In this study, the researcher prepared the data gathered through observation and focusgroup interviews; the transcripts and field notes were also read through to understand the whole context, bearing in mind that the study aimed to understand individual teachers' challenges faced in the teaching of Euclidean geometry in schools, as demonstrated through data collection. The aim was to increase the researchers' understanding of the phenomenon experienced by the participants. In the next stage, the researcher constituted the content areas through extracting and bringing together the text about each topic into one text, which helped the researcher to identify the themes for discussion. Each condensed meaning unit was extracted and labeled with a code and was sorted into subcategories and further extracted into categories. The categories were labeled with content-characteristic names, which were formulated into themes (Nili et al., 2017).

\subsection{Ethical Considerations}

Ethical approval was received from the various authorities before the study was conducted. Ethical clearance was issued from the University of the Free State; approval letters were obtained from the Free State Department of Education as well as from the principals of the participating schools where observations were conducted. Consent forms were signed by participant teachers confirming their willingness to participate in the study. Further consent forms were received from the parents of the under-aged learners, indicating their consent for their children to participate in the study.

\section{Research Results}

In reporting on this research, the direct responses of the ten (10) participants who were observed and interviewed are captured to illustrate the findings. The results are presented according to the following themes: the chalk-and-talk method, the attitude of the teachers and language used, lack of content knowledge, and availability of materials. 


\subsection{Chalk-and-talk method of teaching geometry}

The participating teachers indicated they faced many challenges in the teaching and learning of Euclidean geometry in schools. Regarding teaching and learning strategies, it was evident in the research that the teachers used different teaching and learning strategies in teaching Euclidean geometry. For instance, some of them talk and write during teaching and learning without any explanation for the conceptual understanding of learners. Thus, they only teach without soliciting the opinion/attention of the learners. They completely dominate the teaching and learning processes, which is termed as the talk-and-chalk method of teaching.

Responses from the teachers' focus group interview indicated that the way they were taught geometry while at schools did not develop a good understanding of mathematics. According to the teachers, their teachers read from the textbooks hoping the whole class would understand what was being taught. This was observed when many of the participating teachers make frequent use of mathematics textbooks. It seems that teachers were dependent on texts to write formulae and other theorems on Blackboard before explaining certain concepts to the learners. In many cases, teachers would request learners to open their textbooks to check answers to questions, not feeling confident enough in their answering - this way of teaching modelled how teachers were taught at school where the textbook is vital. Restricting teaching to just the textbook without further application and discussion often results in learners' understanding of not being fully developed. Lack of knowledge of mathematical concepts and inadequate training in the teaching of mathematics at school and higher education level has led to teachers not being well-qualified or experienced in teaching mathematics, particularly challenging topics such as Euclidean geometry. In other words, relevant explanations were inadequate for the teaching of geometry in schools. The following excerpts support the assertion:

Teacher A: As for me, I was forced to teach mathematics since I was redeployed to my current school. I only have a Grade 12 mathematics background, which in most cases, I find it difficult to explain some concepts properly to the learner. I wish the department would send only teachers with mathematics background from the university or diploma to handle this critical subject.

This was observed during classroom observation conducted by the researcher and captured in the video recording. The researcher observed that.

Teacher D: In my college, where I graduated as a teacher, my mathematics lecturer/teacher always uses telling and the textbook methods to teach us whereby individual attention was not given because he always complained about time and finishing of the syllabus. I have stick to that method as the only way I can teach my learners this geometry since I was not introduced to different kinds of teaching strategies during my training.

The teachers indicated that they followed a traditional method of teaching, drawing of how mathematics was taught at school and college. Also, teachers were not introduced to other teaching methods during training, and thus their pedagogical content knowledge is not well-developed to implement during the 
teaching of Euclidean geometry. The teachers felt that the Department was not supportive, that the teachers are often redeployed and placed in schools where they have to teach specific subjects even if they have had little or no training at higher education levels, and felt that they needed to use traditional chalk-and-talk methods of teaching being guided by the textbook. It was evident during observation where teachers were throughout dominant the lessons without given opportunities to learners to express their views or to indicate if they needed clarification on problem areas. In some cases, learners were not attentive and lost focus during teaching and learning. Some teachers had no resources apart from textbooks, and when they were asked why about other resources and materials, they indicated that many resources had been stolen; hence the department has refused to provide them with new resources. The participants also claimed that their colleagues, who were teaching in other schools also used the chalk-and-talk methods and did not allow learners to make use of any practical activities that could help develop their understanding of a concept. The following comment from one of the teachers in one group, Teacher K supports this claim:

"We wish we could use different methods of teaching geometry that would make it easy for learners to understand the concepts."

Two teachers indicated that in their schools, they used one-on-one methods of teaching geometry using many practical activities. They had acquired the skills from the technical colleges where activities/projects were encouraged. They further indicated that they paid attention to the individual styles of learners in the class, which helped focus attention on their learners when teaching Euclidean geometry since it involves various practical activities. The excerpts below support this:

"Sometimes if learners do not understand the concept (geometry), something I try my best to help them individually by making reference to the practical activities that I displayed on the blackboard."

Learning involves the elements of discovery and scaffolding to elevate the learner's activities to a particular level. The scaffolding emphasizes the five levels of geometry thinking and serves as a rational basis for geometry taught in schools. Also, teachers should align their teaching of geometry to the ideas of Piaget (1962) and Van Hiele (1986), who remind us that geometry is needed to enhance and develop learners' skills of visualization needed for identifications and sorting, critical thinking, and problem-solving skills, formulating conjectures, intuition, postulation, deductive reasoning, logical arguments, and proof formulation.

\subsection{The attitude of the teachers to teaching geometry and mathematical language}

The research study showed that some of the teachers displayed negative attitudes towards the teaching of Euclidean geometry since they did not have confidence in teaching mathematics, having been forced to do so by the Department after redeployment. The respondents indicated that those teachers who understood the practical aspects have more confidence in teaching Euclidean geometry than those without practical experience. Most respondents also agreed that teachers' methods of teaching and personality have a considerable impact on the enthusiasm of learners for learning mathematics. Also, the use of mathematical 
language to express a concept should be learner-friendly. Both these aspects are essential since they help learners to understand what is being taught. Teachers' use of mathematical language in the teaching of Euclidean geometry should not be a threat to learners and not contribute a negative attitude towards the subject. This sheds more light on the claim by Adolphus (2011, p.144) when he states that Euclidian geometry is the most problematic area to teach and learn due to the language used, visualization of objects for better identification of properties, and lack of conceptual understanding. Freudenthal (1991) believes that teaching and learning of mathematics geometry need to be precise and should be connected to reality. This means that in the teaching of geometry, teachers should make use of available materials at their disposal to convey the meaning of geometrical concepts which poses a threat to the learning of geometry in schools. Researchers such as Freudenthal (1991), Sanni (2007), Van Den Heuvel-Panhuizen (2003), and Wigley (1994) contend that the teaching approach that connects to reality helps learners develop and apply mathematics to a problem that makes sense to them. In this regard, one teacher had this to say:

"The way we teach mathematics influences learners' enjoyment in mathematics. Therefore, when you teach mathematics without any practical activities, it does not help learners to understand the concepts, which contribute to poor performance in the subject. We must do our best to make the teaching of mathematics enjoyable by making it practical in your teaching."

\subsection{Lack of content knowledge of teaching and learning of geometry}

It also emerged from this study that knowledge of instructional practices for participant teachers was not up to expected standards. As previously mentioned, many teachers were forced to teach mathematics even though mathematics was not their area of specialization, which meant that they lacked subject content knowledge as well as pedagogical content knowledge that would assist them in using a variety of instructional practices. The limited understanding and application of mathematical practices in teaching geometry were also revealed when teachers were observed; for instance, during lesson observation, it became apparent that most participant teachers lacked practical skills, such as planning, demonstration, and organizational skills as well as being able to develop their learners understanding through involvement. Pedagogical content knowledge is the integration of subject expertise and skilled teaching and is considered instrumental in ensuring that teachers deliver effective teaching of geometry. The observation also revealed that some teachers also apportion the blame on learners since learners found it difficult to remember some theorems and as well as basic concepts, which made it difficult for them to teach the concept effectively in schools.

\section{Discussion}

In developing learners' conceptual understanding of Euclidean geometry, Van Hiele's (1986) five levels of geometry thinking should be taken into consideration and followed. It emerged from this study that the knowledge of instructional practices of participant teachers for teaching and learning of Euclidean geometry did not embrace the vital five levels and, therefore, both teaching and learning were poor. Only a few teachers exhibited acceptable standards of teaching. In 
many cases, deployment has meant that teachers were forced to teach subjects like mathematics despite having had little or no training. This confirms a statement by Turik (2000), which alluded to a lack of basics and inadequate teacher background in mathematics topics, thus engendering negative attitudes towards the latter. Teaching such a topic was, therefore, a challenge. It was observed that both teachers' content knowledge and the pedagogical content knowledge of teaching mathematics were questionable since many of them could only teach some geometry concepts with the help of textbooks and were unable to use a variety of approaches or strategies to apply the mathematical knowledge. Given this, one teacher had this to say:

"Indeed, a lot of mathematical modelling activities which they think will play an essential role in teaching mathematics could have been given by the departmental officials through workshops and seminars. This could have helped our skills in teaching geometry in schools. We teach those topics with no prior knowledge simply because we are being forced to teach due to redeployment."

This excerpt reveals that lack of support from the Department of Basic Education created uncertainty among some teachers as they were put in positions where they were ill-equipped to teach the specific subject, resulting in negative attitudes, mainly towards the teaching of mathematics. This is in line with the findings by Maree \& Van der Walt (2007); Masinga et al. (2007), Strawderman (2010), and Webb (2010), who stated that there are several Mathematics teaching studies, which focus on teachers' content knowledge, curriculum implementation, instructional strategies, teachers' competency in teaching the new mathematics curriculum and teacher education programs. However, some teachers are qualified as teachers but have not undergone training on newly-introduced topics like Euclidean geometry and therefore find it difficult to teach due to lack of support and training offered by the Department of Basic Education as well as institutions of higher learning for development.

Practical instruction in geometry teaching, and learning and any topic in mathematics for that matter, requires a teacher to develop sound mathematical knowledge as well as instructional skills and strategies making use of useful resources and activities that guide the teaching activities and further assist in the effective delivery of the lesson (Luneta, 2014). Teaching without good instructional skills and modelling activities and sound knowledge of the concept usually puts the teacher in a challenging situation, and learners tend to lose interest in the topic. As a result, quality teaching is compromised. It is, therefore, crucial that mathematics teachers are fully equipped with sound knowledge and are aware of the teaching environment and their learners. This will ensure that appropriate modelling activities are used in problem-solving.

Teachers need to adapt their instructional approach or strategy to teaching various concepts by engaging in a variety of practical ways that assist in developing learners' understanding of the concepts under discussion. Teachers should also try to draw learners' attention to alternative solutions to mathematical problems through reflection-on-action. It is believed that teachers are more likely to reflect on their teaching to improve teaching practice when they understand 
the curriculum visions (Khoza, 2016). Practical instruction in any topic requires teachers to develop sound instructional strategies and knowledge of useful resources and activities (Luneta, 2014) as this allows teachers to gauge the depth of their learners' understanding of a concept. This contradicts the findings by Sanni (2007), which stated that instruction of geometry concepts was bedevilled regimented mathematics classroom practices such as checking homework, followed by teacher lecture and demonstration, followed in turn by learner practice in a sequence of classroom instructional activities. These aspects do not take into account Van Hiele's (1986) five levels of geometry thinking, which serve as a rational basis for the teaching of geometry in schools.

Teachers who are capable of making detailed and explanatory lessons plans can address misconceptions of mathematical concepts that learners experience in the classroom. They can explain the difficulties that learners encounter during teaching and learning by pre-empting them. Knowledge of instructional practices involves curriculum, tasks, and tools for teaching and incorporates both subject and pedagogical content knowledge (Ball et al., 2008; Shuman, 1986).

The analysis of the study further revealed that lack of understanding of mathematical concepts and inadequate training in the teaching of mathematics at school and higher education level has led to teachers not being well-qualified or experienced in teaching mathematics, particularly challenging topics such as Euclidean geometry. This is in line with the assertion by Brown (1999) and Khoo and Clements (2001) that in many instances, geometry teaching is based on immersive and adaptive instruction and learning where teachers shift from a conceptual approach (the sensible application of procedures) to a procedural approach (calculation accuracy). However, many learners fail to develop an adequate understanding of geometrical concepts or demonstrate reasoning and problem-solving skills. This contradicts the primary mission of the Department of Education, where much emphasis is to produce competent teachers. They can offer the necessary services in the community, such as in the Motheo district of the Free State, through quality teaching and learning (Teacher's Forum, 2009).

\section{Conclusions}

The findings of the research revealed that teachers' performance in class was due to a lack of knowledge of mathematical knowledge and instructional practices. Teachers face challenges when teaching Euclidean geometry in schools. Thus their lack of knowledge and application has led to the chalk-and-talk method predominantly being used guided by textbooks. Teachers felt there was a lack of support from the Department, little training, and the issue of redeployment, which means that teachers lacked content as well as pedagogical knowledge due to being required to teach a subject with which they were not familiar. As a result, teachers' attitudes towards mathematics and the teaching of Euclidean geometry, specifically, were affected. The findings of the study have helped the researcher to embark on developing training for mathematics teachers in collaboration with the Department of Basic Education using mathematical modelling activities as well as relevant skills and strategies in the teaching of geometry in schools for a better understanding of learners. 


\section{Recommendations}

From the findings of this study, it is essential for further research of the same kind to be conducted on a large scale (that is a quantitative manner) where different opinions of teachers from other areas can be hard to establish whether or not the same problems occur when teaching Euclidean geometry in schools. As South Africa needs suitably-qualified mathematics teachers who can teach the subject effectively to overcome the problem of poor performance and the high failure rate in mathematics, further research is required. Findings from such a study could assist in ensuring quality mathematics education, which will develop the necessary skills needed by doctors, scientists, and many other scientificallyoriented professionals.

\section{References}

Adolphus, T. (2011). Problems of Teaching and Learning of Geometry in Secondary Schools. Nigeria, Department of Education: River State University of Science and Technology. Retrieved from http://hdl.handle.net/1893/26189

Alex, J., \& Mammen, K. J. (2018). Students' understanding of geometry terminology through the lens of Van Hiele theory. Pythagoras, 39(1), pp.1-8. https://doi.org/10.4102/pythagoras.v39i1.376

Ball, D., Thames, M., \& Phelps, G. (2008). Content Knowledge for Teaching What Makes It Special? Journal of Teacher Education. 59. https:// doi.10.1177/0022487108324554

Bassarear, T. (2012). Mathematics for elementary school teachers (5 $5^{\text {th }}$ Ed.). Cengage Learning.

Binti, N., Tay, I., \& Lian, B. (2004). Teaching and Learning of Geometry: Problems and Prospect. Masalah Pendidikan Jilid, 27, 165-178.

Brannan, D. A., Esplen, M. F., \& Gray, J. J. (2002). Geometry. Cambridge University Press.

Brodie, K., Jina, Z., \& Modau, S. (2009). Challenges in implementing the new mathematics curriculum in Grade 10: A case study. African Journal of Research in Mathematics, $\begin{array}{llll}\text { Science and Technology Education, 13(1), 19-32. } & \text {. }\end{array}$ https:// doi.org/10.1080/10288457.2009.10740648

Brown, A. R. (1999). Geometry's giant leap. The Mathematics Teacher, 92(9), 816-819. https://doi.org/10.5951/MT.92.9.0816

Chihambakwe, T. (2017). Impact of national senior certificate examination diagnostic report on learner performance in mathematics (Unpublished Masters dissertation). University of Zululand, Pietermaritzburg

Cohen, L., Manion, L., \& Morrison, K. (2009). Research methods in education. Routledge.

Creswell, J. W. (2009). Research design: Qualitative, quantitative, and mixed methods approaches ( $3^{\text {rd }}$ Ed.). SAGE Publications.

Department of Basic Education (DBE). (2011). Curriculum and assessment policy statement (CAPS), Grade 10-12, Mathematics. Government Printing Works.

Ding, L., \& Jones, K. (2006). Teaching geometry in lower secondary school in Shanghai, China. Proceedings of the British Society for Research into Learning Mathematics.

Freudenthal, H. (1991). Revisiting mathematics education: China lectures. Kluwer Academic Publishers.

Güven, B., \& Kosa, T. (2008). The effect of dynamic geometry software on student mathematics teachers' spatial visualization skills. Turkish Online Journal of Educational Technology-TOJET, 100-107. http:// doi:10.1016/j.sbspro.2010.12.169

Jones, K. (2002). Issues in the teaching and learning of geometry. Routledge. 
Jones, K., \& Tzekaki, M. (2016). Research on the teaching and learning of geometry. In A. Gutiérrez, G. Leder \& P. Boero (Eds.), The Second Handbook of Research on the Psychology of MathematicsEducation: The Journey Continues (pp. 109-149). Sense. http://dx.doi.org/10.1007/978-94-6300-561-6_4

Khoo, S. C., \& Clements, M. A. (2001). A-level Students' Understanding of Lower Secondary School geometry. In K. Y. Wong, H. Tairab, \& M. Clements, Proceedings of the Sixth Annual Conference of the Department of Science and Mathematics Education: Energising Science, Mathematics and Technical Education for all (pp. 213-222). University of Brunei.

Khoza, S. B. (2016). Is teaching without understanding curriculum visions and goals a high risk? South African Journal of Higher Education, 30(5), 104-119. http://doi:10.20853/30-5-595

Kotzé, G. (2007). Investigating shape and space in mathematics: a case study. South African Journal of Education, 27(1), 19-35.

Luneta, K. (2014). Foundation phase teachers'(limited) knowledge of geometry. South African Journal of Childhood Education, 4(3), 71-86. https://doi.org/10.4102/sajce.v4i3.228

Luthuli, D. (1996). Questions, reflection and problem posing as sources of inquiry in Euclidean geometry. Pythagoras, 40, 17-27.

Mamali, N.R. (2015). Enhancement of learner's performance in geometry at secondary schools in Vhembe District of the Limpopo Province (Doctoral dissertation).

Maree, K., \& van der Walt, M. (2007). Do mathematics learning facilitators implement metacognitive strategies? South African Journal of Education, 27(2), 223-241.

Masinga, A., Mhlongo, M., \& Luneta, K. (2007). Implementing Curriculum change: Addressing poverty, gender equity and optimizing learning. University of Witwatersrand.

Mcintyre, R. N. I. (2018). Analysing geometry in the Classroom Mathematics and Mind Action Series mathematics textbooks using the van Hiele levels. (Unpublished Masters Dissertation). University of Witwatersrand.

Morris, R. (1985). Studies in mathematics education: The education of secondary school teachers of mathematics. UNESCO.

Nili, A., Tate, M., \& Johnstone, D. (2017). A Framework and Approach for Analysis of Focus Group Data in Information Systems Research. Communications of the Association for Information Systems, 40(1), 1-21. https://doi.org/10.17705/1cais.04001

Piaget, J. (1962). The stages of the intellectual development of the child. Bulletin of the Menninger Clinic, 26(3), 120.

Pusey, E. L. (2003). The Van Hiele model of reasoning in geometry: a literature review. Retrieved from https:// repository.lib.ncsu.edu/bitstream/handle/1840.16/2275/etd. pdf? sequence $=1 \&$ isAllowed $=y$

Sanni, R. (2007). Teaching geometry in schools: an investigative rather than instructive process. Pythagoras, 2007(65), 39-44. https:// doi.org/10.4102/ pythagoras.v0i65.90

Saxe, G. B. (1991). Culture and cognitive development, Studies in mathematical understanding. Lawrence Erlbaum Associates.

Shulman, L. S. (1986). Those who understand: Knowledge growth in teaching. Educational researcher, 15(2), 4-14.

Solis, A. (2009). What matters most in the professional learning of content teachers in classrooms with diverse student populations. IDRA Newsletter by the International Development Research Association. 
Strawderman, V. W. (2010). Math anxiety model. Math Goodies. Retrieved from https://www.mathgoodies.com/articles/math_anxiety_model

Tirosh, D., \& Graeber, A. O. (2003). Challenging and changing mathematics teaching classroom practices. In A. Bishop, M. K. Clements, C. Keitel-Kreidt, J. Kilpatrick \& F. K. S. Leung (Eds.), Second international handbook of mathematics education (pp. 643-687). Springer.

Ubah, I., \& Bansilal, S. (2019). The use of semiotic representations in reasoning about similar triangles in Euclidean geometry. Pythagoras, 40(1), pp. 1-10. https:// doi.org/10.4102/ pythagoras.v40i1.480

Van de Walle, J. A., Karp, K. S., \& Bay-Williams, J. M. (2013). Elementary and middle school mathematics: Teaching developmentally ( $8^{\text {th }}$ Ed). Pearson.

Van Den Heuvel-Panhuizen, M. (2003). The didactical use of models in realistic mathematics education: An example from a longitudinal trajectory on percentage. Educational studies in Mathematics, 54(1), 9-35. https:// doi.org/10.1023/B:EDUC.0000005212.03219.dc

Van Hiele, P. M. (1986). Structure and insight. Academic Press.

Webb, D. C. (2012). Teacher change in classroom assessment: The role of teacher content knowledge in the design and use of productive classroom assessment. In S.J. Cho (Ed.), Proceedings of the 12th International Congress on Mathematical Education: Topic Study Group (pp.6773-6782). Springer.

Wessels D. C. J. (2004). Subject didactics mathematics/mathematics education, Tutorial Letter SDMATO-4/501/2004. Unisa.

Wigley, A. (1994). Models for mathematics teaching. In A. Bloomfield \& T. Harries (Eds.), Teaching and learning mathematics (pp. 22-25). Association of Teachers of Mathematics.

Xei, M. (2005). Postmodernist, mathematical view and mathematics education. Normal University Press. 